\title{
Rules Are Made to Be Broken, or the Menuetto of Beethoven's Op. 2, No. 1
}

Regras existem para serem quebradas, ou o Menuetto da Sonata Op. 2, No 1, de Beethoven 


\section{Abstract}

A striking gesture appears at the climax of the first phrase of the Menuetto from Ludwig van Beethoven's Sonata for Piano in F minor, Op. 2, No. 1. This motivic gesture, which may be understood as derived from manipulation of standard voice-leading procedures, has intriguing ramifications that deeply affect the structure and narrative of the entire movement. These features are explored with the aid of Schenkerian analytic procedures, and the analysis is then compared to an interpretation of this same movement by Heinrich Schenker.

Keywords: Beethoven, motive, Schenkerian analysis, Tonwille.

\section{Resumo}

Um gesto marcante aparece no clímax da primeira frase do Menuetto da Sonata para Piano em Fá menor, Op. 2, No.1 de Ludwig van Beethoven. Este gesto motívico, que pode ser entendido como derivado da manipulação de procedimentos contrapontísticos padrão, tem ramificações inusitadas que afetam profundamente a estrutura e a narrativa de todo o movimento. Estas características são exploradas com a ajuda de procedimentos analíticos schenkerianos, e a análise é então comparada a uma interpretação deste mesmo movimento por Heinrich Schenker.

Palavras-chave: Beethoven, motivo, análise Schenkeriana, Tonwille.

1 L. Poundie Burstein is Professor of Music Theory at Hunter College and the Graduate Center of the City University of New York. His primary areas of interest include Schenkerian analysis, analysis of eighteenth century music, music theory pedagogy, and form studies. He has also taught at Mannes College, Columbia University, Queens College, and held an endowed chair at University of Alabama in 2010. Distinguished Teaching Award from the New School University, and in 2008 he received the Outstanding Publication Award of the Society of Music Theory (SMT). He is a former President of the Society for Music Theory. 


\section{The first half of the Menuetto}

Among the most exciting passages in music are those that seem to transcend their stylistic context by "breaking the rules." Such instances present harmonic, contrapuntal, and melodic devices that depart from the compositional decorum typical of their time and place, thereby risking coming across as crude or gauche. Yet if skillfully handled, these violations of stylistic norms can have a powerful expressive impact and contribute significantly to a composition's deeper logic.

Bold gestures that seem to deviate from the standard guidelines of their style, but which nevertheless are deftly integrated within a larger compositional framework, are particularly emblematic of the music of Ludwig van Beethoven. A straightforward and yet fascinating example of this may be witnessed in the Menuetto from Beethoven's very first piano sonata, his Sonata for Piano in F Minor, Op. 2, No. 1. At the climax of this movement's first phrase, a jarring melodic figure appears. As the movement unfolds, the repercussions of this gesture continue to reverberate, in a manner that deeply colors the movement's underlying structure and drama.

This unruly melodic figure arises on the last beat of in $\mathrm{m} .12$, in the pickup to the following measure (Fig. 1). At this point, G, the leading tone of the local key of A-flat, appears as the highest note within its phrase. As such, this leading tone fails to resolve upward to the tonic, as would be normal. The resulting effect is unmistakably harsh, and its unsettling effect is further emphasized by a sforzando that causes the two notes at the end of $\mathrm{m}$. 12 to stick out from their surrounding piano dynamics.

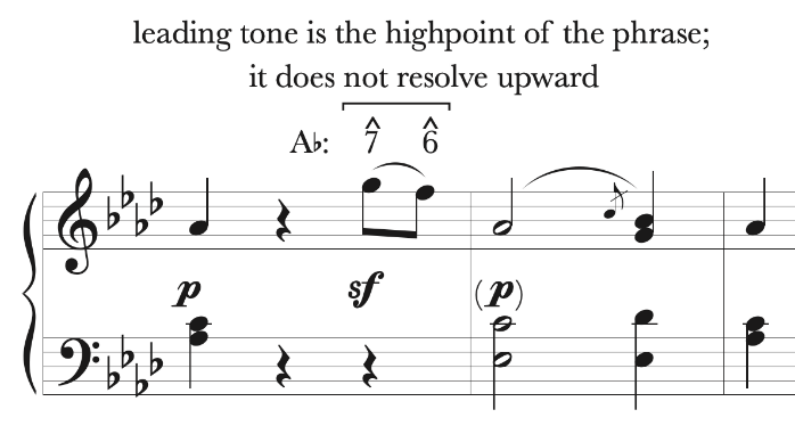

Fig. 1. Ludwig van Beethoven, Sonata in F minor, Op. 2, No. 1, Menuetto, mm. 12-14: harsh melodic gesture of m. 12.

The climatic gesture of $\mathrm{m} .12$ clearly would be out of place in a basic harmony or counterpoint exercise. Nonetheless, its voice leading could be contrapuntally justified by appealing to the concept of register transfer (transferência de registro), in which an implied melodic line is shifted up or down an octave. ${ }^{2}$ To help see how the register transfers may be understood to unfold here, consider $\mathrm{m} .12$ within the context of its entire phrase, which forms the A section of this rounded binary form movement (Fig. 2).

2 Regarding transferência de registro, see GERLING; BARROS, 2020, pp. 36-37. 

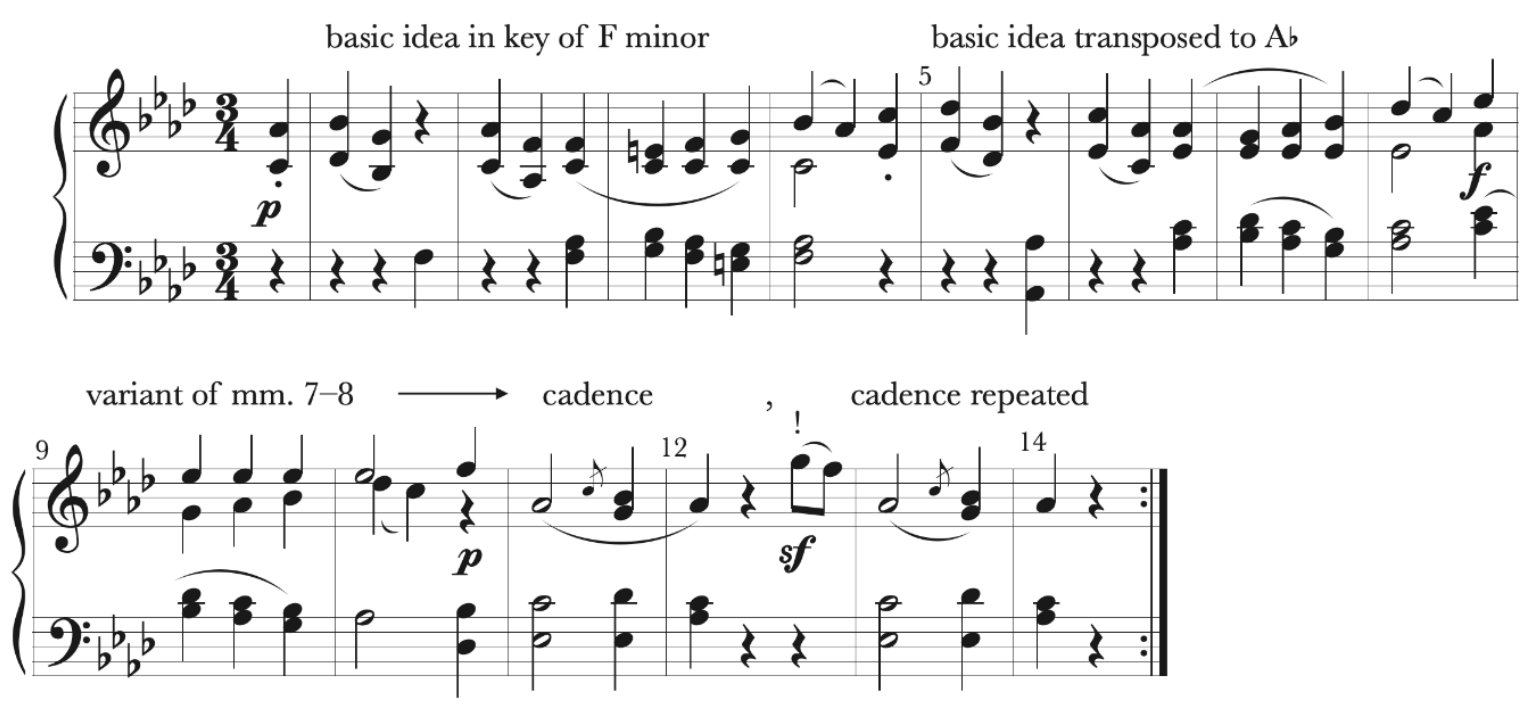

Fig. 2. A section: mm.1-14.

As highlighted by the annotations in Fig. 2, the opening phrase of this movement is constructed in the manner of a modulating sentence. Within this modulating sentence, the basic idea of $\mathrm{mm}$. 1-4 establishes the home key of $\mathrm{F}$ minor by prolonging tonic harmony with inverted dominant chords. As the voice-leading interpretation of Fig. 3 shows, during this passage the upper voice outlines a polyphonic melody that embellishes a top-voice A-flat with neighbor motion. This top-voice neighbor figure is itself counterpointed by a motion to the inner voice (movimento a partir de uma voz interna), A-flat-G-F, followed by a motion back to A-flat. ${ }^{3}$

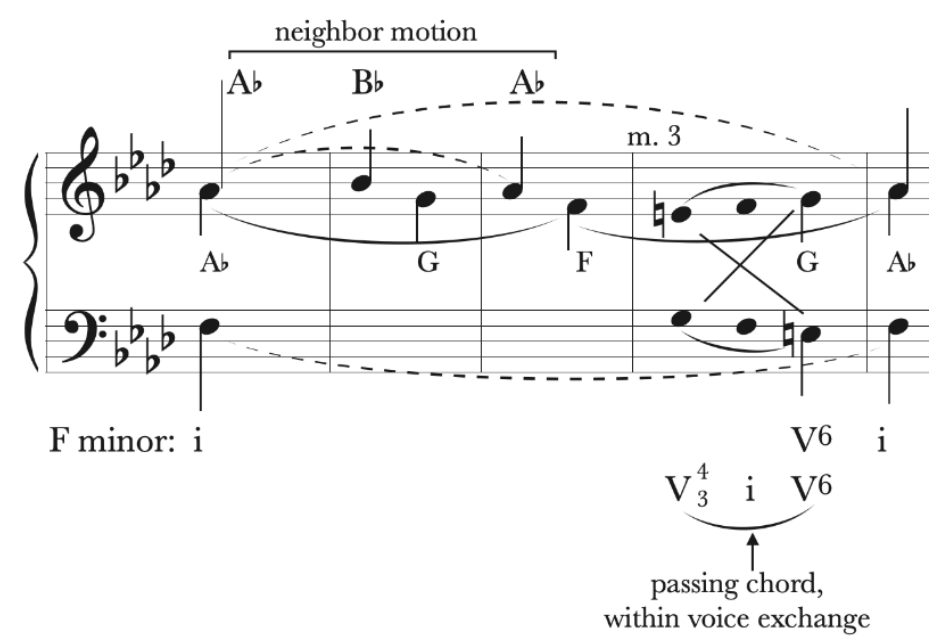

Fig. 3. Voice-leading sketch of $\mathrm{mm}$. 1-4.

3 Regarding movimento a partir de uma voz interna, see GERLING; BARROS, 2020, pp. 21-22. Regarding the concept of the voice exchange (troca de vozes), such as highlighted in $\mathrm{m}$. 3 of Fig. 3, see GERLING; BARROS, 2020, p. 38. 
As the phrase continues, the basic idea returns slightly varied and transposed to the key of A-flat in $\mathrm{mm}$. 5-8, followed by a repetition of its last two bars in mm. 9-10 and then a cadence (see annotations in Fig. 2 above). To put the voice leading of mm. 1-14 in relief, Fig. 4a presents an abstract model of the Menuetto's entire opening phrase. In this model, the register transfers found in Beethoven's composition are omitted so that the upper voices in Fig. 4a move smoothly from one chord to the next. Fig. $4 \mathrm{~b}$ reinstates these register transfers, with the inner voices shifted up an octave in two places. Owing to these register transfers, the melody surges upward as the phrase approaches its climax.

(a)

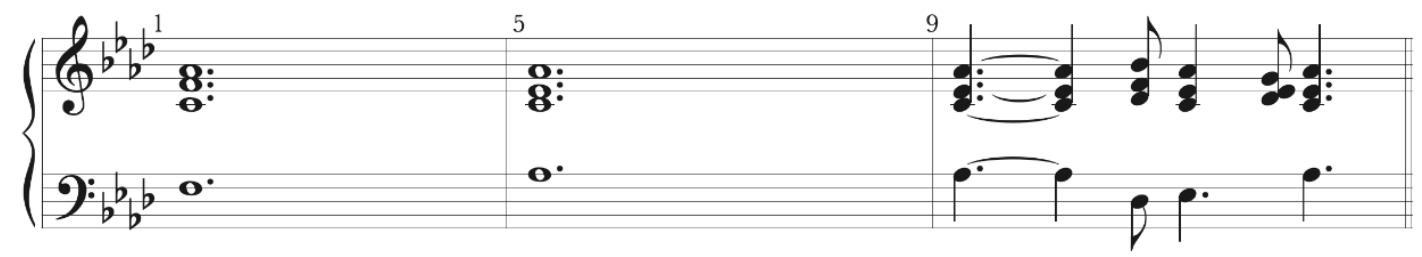

(b)

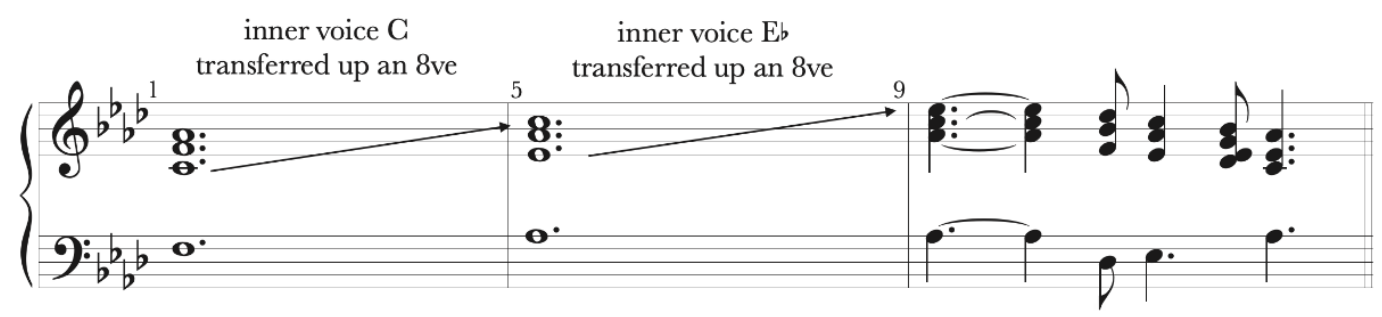

Fig. 4. Voice-leading models of mm. 1-14.

(a) Voice-leading model in which the motion in the upper voices is stepwise.

(b) Variant of Fig. 4a, in which notes from the inner voice are twice shifted upward by an octave.

A melodic descent to the tonic in this phrase's final measures counterbalances the upward melodic surge in mm. 1-9. As depicted in Fig. 5, mm. 10-12 could be understood as derived from a voice-leading model in which the melody moves down in a straightforward manner from E-flat to A-flat. In the first stage of this model, the top line is completely stepwise (Fig. $5 a)$. In the next stage, a register transfer of a neighbor figure from the inner voice causes the first notes of this descending line to be embellished by the cover tones (notas de cobertura) E-flat-F-E-flat (Fig. 5b). ${ }^{4}$ And in the model's last stage, the final note of this E-flat-F-E-flat neighbor figure is abruptly transferred down an octave (Fig. 5c).

4 Regarding notas de cobertura, see GERLING; BARROS, 2020, p. 24. 
(a)

(b)

(c)

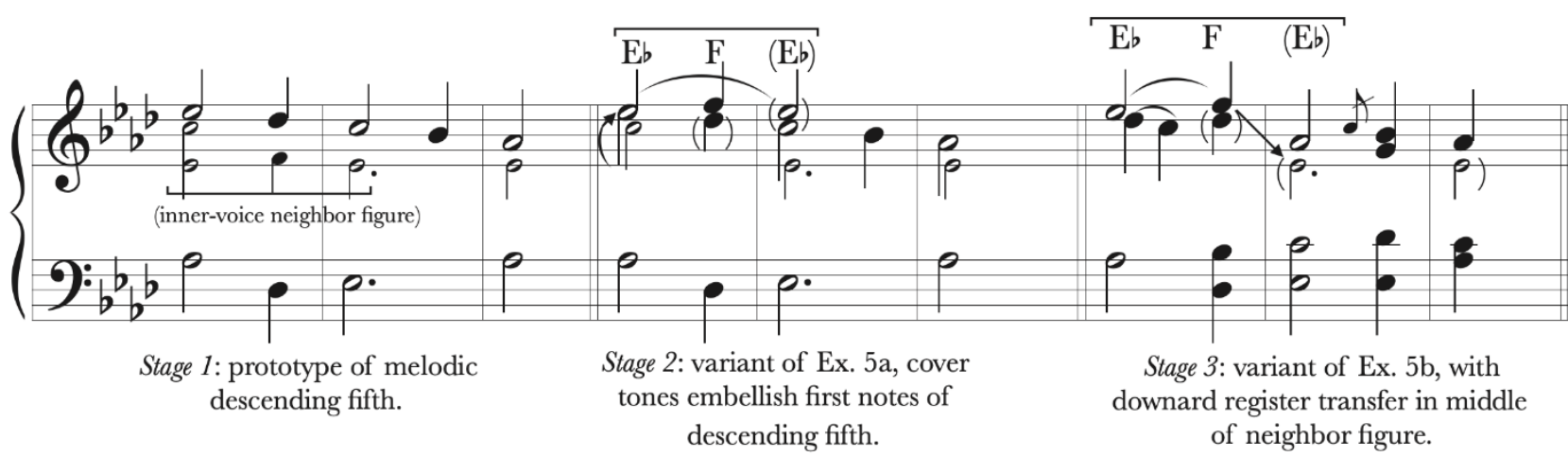

Fig. 5. Proposed voice-leading derivation of mm. 10-12, in three stages.

The cadence of $\mathrm{mm} .10-12$ is then echoed in $\mathrm{mm} .12-14$. During this repetition of the cadence, the neighbor-tone $\mathrm{F}$ is itself decorated by an incomplete neighbor tone, $\mathrm{G}$ (Fig. 6a). This embellished neighbor tone-emphasized by an upward register transfer and then immediately after by a downward register transfer-in turn gives rise to the bold melodic figure of $\mathrm{m} .12$ (Fig. 6b).

(a)

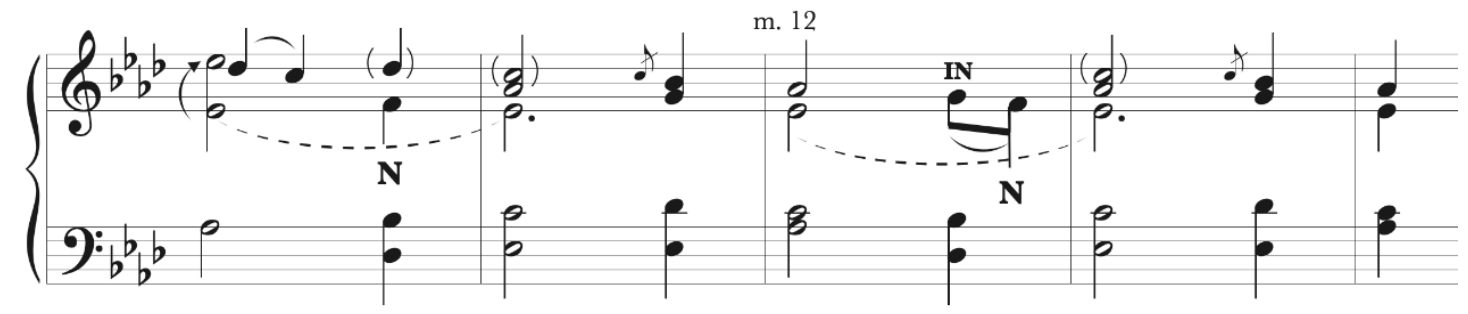

(b)

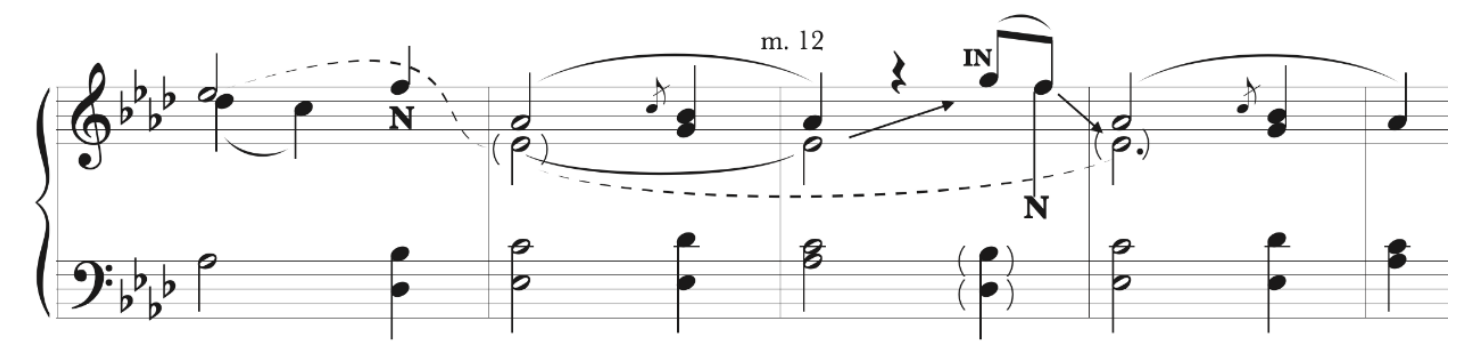

Fig. 6. Proposed voice-leading derivation of upper voice in $\mathrm{mm}$. 10-14.

(a) Sketch depicting G of m. 12 as incomplete neighbor (IN) to an F neighbor tone (N) in an implied inner voice (and with register transfers omitted).

(b) Variant of Fig. 6a, with register transfers (cf. Fig. 1). 
It is instructive to compare the models presented in Fig. 6a and b. In Fig. 6a, the G of m. 12 functions as an incomplete neighbor to the neighbor-tone $F$, within an implied alto voice. Since it is couched within an inner voice, the maneuver of $m .12$ causes little disturbance within Fig. 6a, for in this context it fits comfortably within the norms of standard classical harmony and counterpoint. In Fig. 6b, on the other hand, which more closely matches what happens in Beethoven's actual composition, the notes $\mathrm{G}$ and $\mathrm{F}$ are suddenly shifted up and down an octave, as though quickly summarizing the up-down motions of the previous measures. These sudden shifts expose the unresolved leading tone of $\mathrm{m} .12$, thereby enhancing its harsh effect. Yet despite its harshness, this gesture could be understood as derived from rather standard harmonic-contrapuntal procedures, as is suggested by comparing the voice-leading models of Exx. $6 a$ and $b$.

Demonstrating a possible voice-leading derivation for the climactic gesture of $\mathrm{m} .12$ by no means denies its shocking effect, however. On the contrary, such analysis helps highlight the surprising nature of this gesture by contextualizing it, underlining the distance of what Beethoven composed from its more normative contrapuntal basis. Indeed, as is discussed in the next section of this essay, the remainder of the Menuetto could be understood as an attempt to deal with the ramifications created by the surprising melodic twist of $\mathrm{m} .12$.

\section{Second half of the Menuetto}

The motive first seen in of $m .12$ returns at key moments within the Menuetto's second half. During these subsequent appearances, the motive is altered through rhythmic expansion, transposition, chromatic alteration, or some combination of these techniques. In its altered guises, the harsh effect that accompanied the original appearance of the motive is increasingly mollified, as though the music is striving to reconcile the motive within its environment.

The B section ( $\mathrm{mm} .15-28$ ) that opens the Menuetto's second half begins with a varied repetition of the first segment of the main theme's basic idea, now sequencing upward from the key of A-flat major to B-flat minor (Fig. 7a). A cadence in $\mathrm{mm}$. 20-22, which confirms the local key B-flat minor, recalls the cadential gesture from $\mathrm{m}$. 12. Significantly, however, the notes here do not form a strict transposition of the original motive (Fig. 7b). In m. 12, the motive outlined scale-degrees $\hat{7}-\hat{6}$. Thus, in its initial appearance, the motive's opening notethe leading tone A-flat-moved downward, contrary to its naturally ascending tendency. In $\mathrm{m} .20$, on the other hand, the motive is transformed to $\hat{6}-\hat{5}$ of B-flat minor. In this changed format, the motive's opening note follows its naturally descending tendency, thereby softening the harshness associated with the motive's initial appearance. Ironically, although the altered transposition in $\mathrm{m}$. 20 does not match the scale degrees of the motive from $\mathrm{m}$. 12, it does more closely echo its pitches (compare G-flat-F m. 20 to G-F in m. 12). Notice also the sforzando s underneath the gestures of both $\mathrm{m} .12$ and $\mathrm{m} .20$-the only sforzandos thus far in the movement-which further draw attention to these gestures' connection to each other. 
(a)

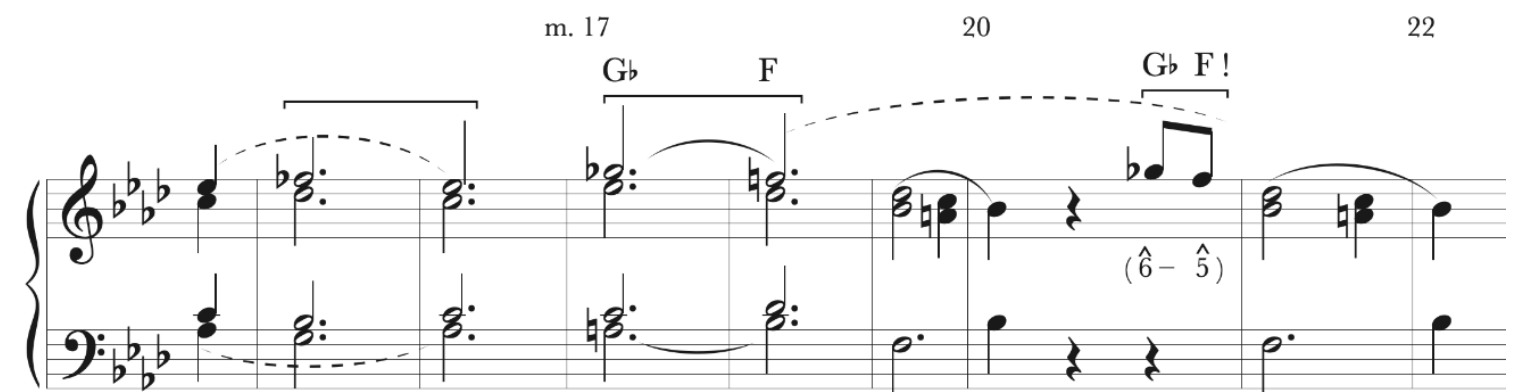

Ab: I

viio7

I

Bb min.: viio7

V i

V i

(b)
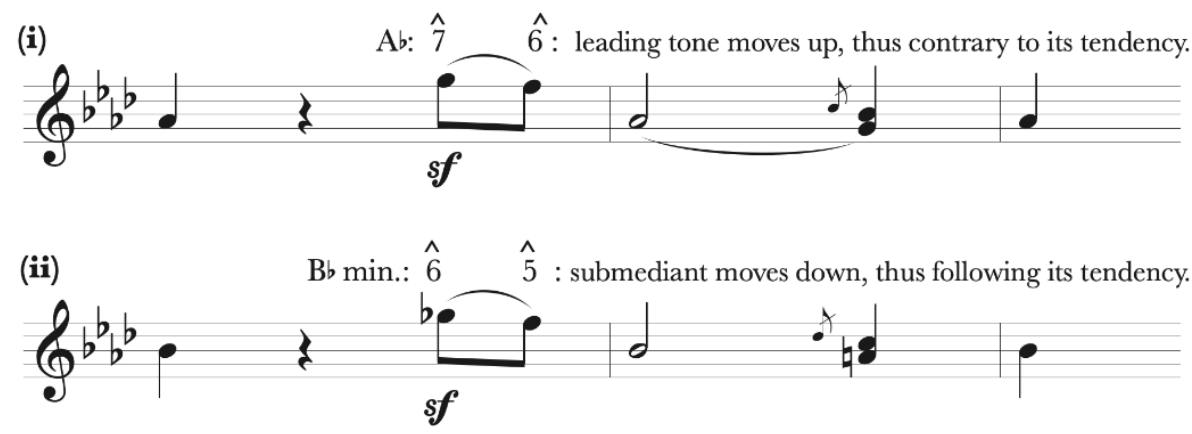

Fig. 7. Models that highlight the interactions of the motive from m. 20.

(a) Rhythmic reduction of mm. 15-22.

(b) Comparison of motive from mm. 12 and 20: (i) mm. 12-14; (ii) mm. 20-22.

The altered form of the motive in $\mathrm{m} .20$ in turn helps call attention to a latent motivic connection. As suggested by the brackets in Fig. 7a, the G-flat-F of the basic idea in $\mathrm{m}$. 17-18 anticipates - in a rhythmically augmented form-the G-flat-F of the motive from $\mathrm{m}$. 20. As a result, the motive that first appeared in $\mathrm{m}$. 12 is retrospectively heard as intimately connected to the basic idea of the main theme.

The cadence of mm. 20-22 is twice gently echoed, at a pianissimo dynamic level, in mm. 22-24. Then, as though suddenly awakening from a slumber, the following measures burst forth to drive in a furious manner toward a half cadence the home key. This fortissimo drive toward V of F minor ( $\mathrm{mm}$. 24-28), reinforced by doubling in octaves, touches on an implied tonic harmony of $\mathrm{F}$ in its middle, in $\mathrm{m}$. 27. However, this metrically deemphasized tonic chord surely is to be understood as couched within a larger motion from iv (through i) to V. In this context, it forms the midpoint of a descending fourths sequence in the bass, from B-flat to $F$, then from $F$ to $C$ (Fig. 8). 
(a)

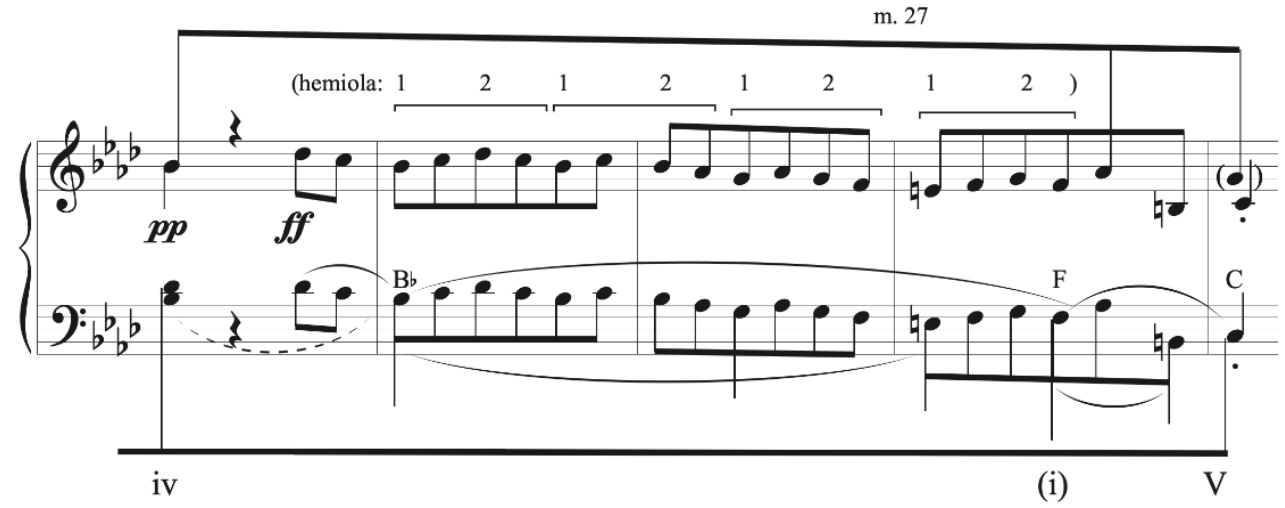

(b)

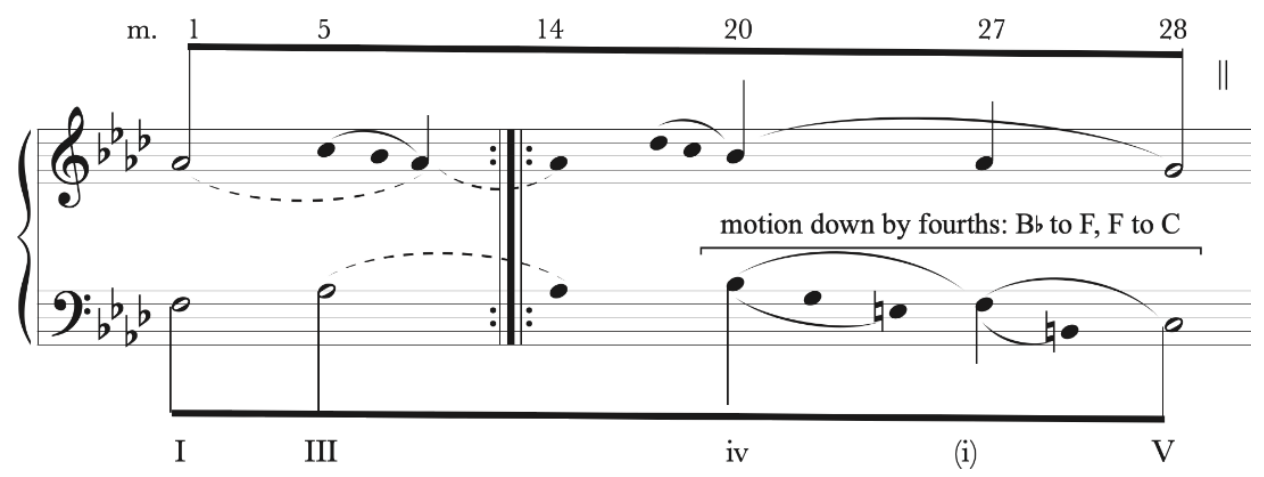

Fig. 8. Retransition at end of $B$ section.

(a) Detailed voice-leading sketch of mm. 24-28.

(b) Voice-leading sketch of mm. 1-28, detailed for mm. 20-28.

The main theme returns at the start of the ensuing $A^{\prime}$ section ( $\left.\mathrm{mm} .28-40\right)$. Seemingly riled by the thrilling flourish at the end of the $B$ section that precedes it, the ensuing $A^{\prime}$ section now enters at a loud dynamic level, thereby contrasting with the piano dynamics of the opening A section. The design of the main theme appears to be caught up in the excitement here as well. Accordingly, at the outset of the $A^{\prime}$ section only the first two measures of the main theme's basic idea return, repeated in invertible counterpoint as the melody surges upward to D-flat, the highest note within the Menuetto (Fig. 9). Adding to the sense of instability, the reappearance of the tonic $F$ in the bass is delayed until $m$. 30. The drive toward the cadence in F minor that follows is particularly electrifying, filled with trills and sforzandos as the melody 
and bass lines move in contrary motion. Surprisingly, upon reaching the climactic cadence of $\mathrm{mm} .35-36$, the dynamics suddenly decrease to piano, wrapping up the phrase in an almost mysteriously poignant manner.

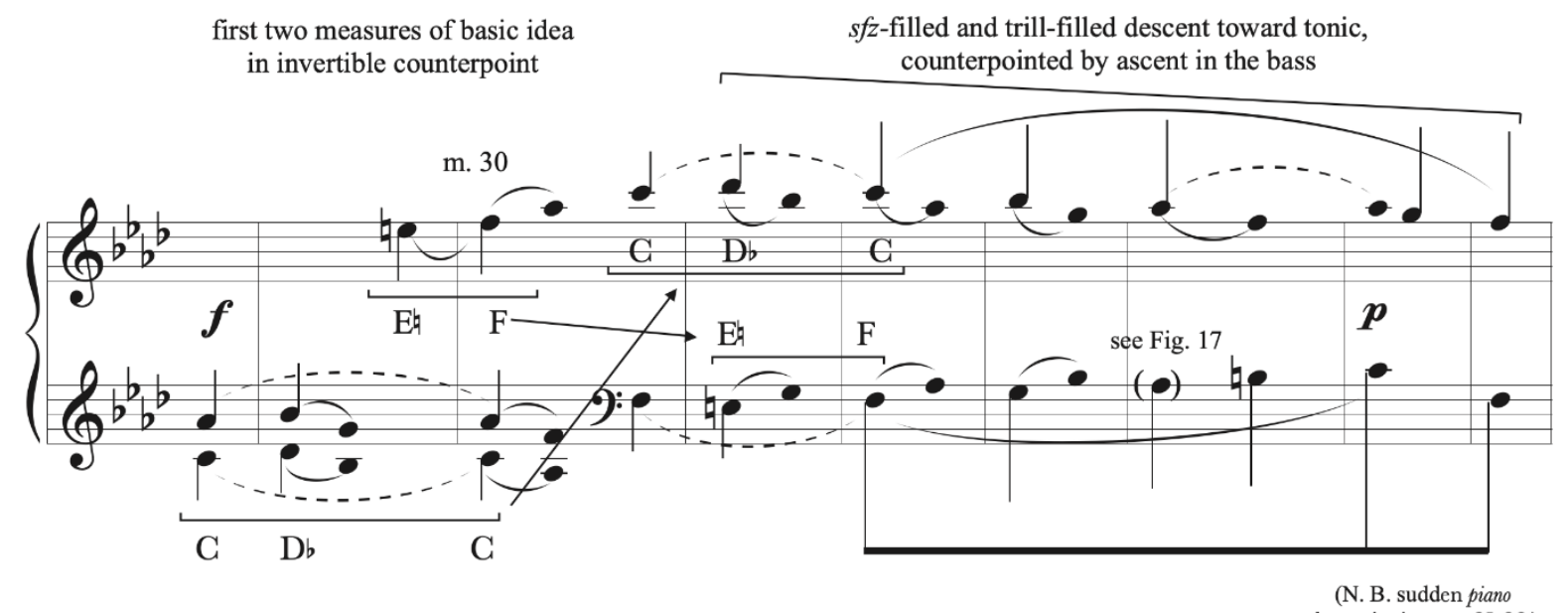

Fig. 9. Voice-leading sketch of $A^{\prime}$ section, mm. 28-36.

The cadence of $\mathrm{mm} .35-36$ is faintly echoed at an even softer dynamic level in $\mathrm{mm}$. $37-38$, as the melody now returns to its original, "obligatory register" (registro obrigatório). ${ }^{5}$ At this point, the initially disruptive motive of $m .12$ reappears for a final time (Fig. 10). By now, however, this motive has been stripped of its former shrillness. For instance, the first pitch of this motive in $\mathrm{m} .36$ is approached not by an upward leap of a major seventh, but by a step downward. Also, the upward-tending leading tone of $\mathrm{m} .12$ is replaced in $\mathrm{m}$. 36 by a downward-tending subtonic. Furthermore, the pianissimo dynamic level of the motive in $\mathrm{m}$. 36 substitutes for the former sforzando attack witnessed in bar 12 . These factors all combine to remove the harshness that was associated with the motive during its first appearance. $A$ second and final, simpler echo of the cadence in $\mathrm{mm}$. 39-40 wraps up the movement in a gentle manner.

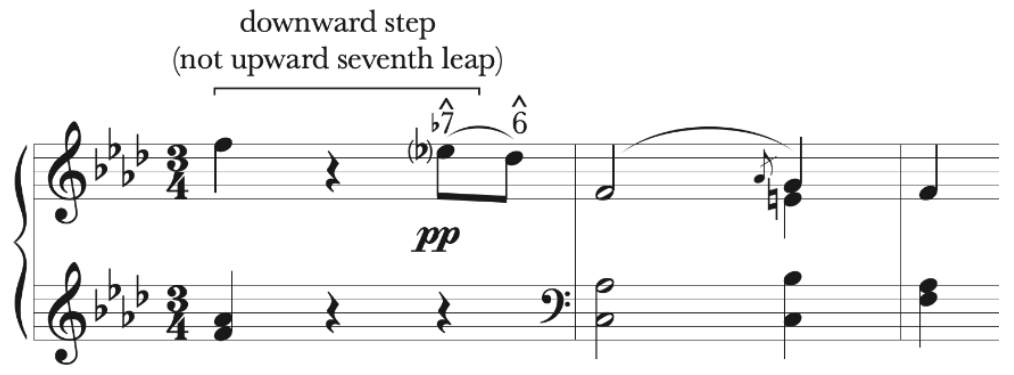

Fig. 10. Quotation of mm. 36-38 (cf. Fig. 1).

Fig. 11 proposes voice leading sketches for the entire Menuetto, with the appearances of

5 Regarding the registro obrigatório, see GERLING; BARROS, 2020, p. 31. 
the motive discussed above highlighted by brackets and arrows. Fig. 11a depicts an interpretation of the underlying harmonic framework. Fig. 11b provides a detailed sketch in which the registral transfers found in the composition have been removed, so that the voice-leading in the upper voices is smooth throughout. Fig. 11c reinstates the registral transfers, thereby more closely matching the octave shifts found in the actual composition.

(a)

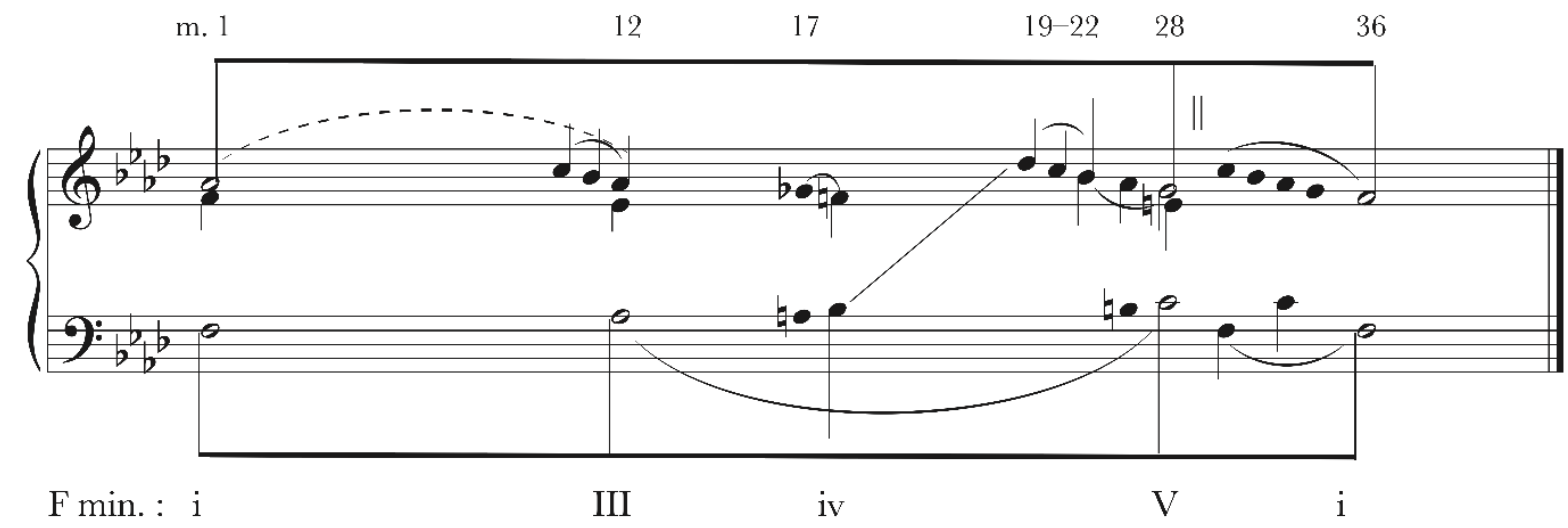

(b)

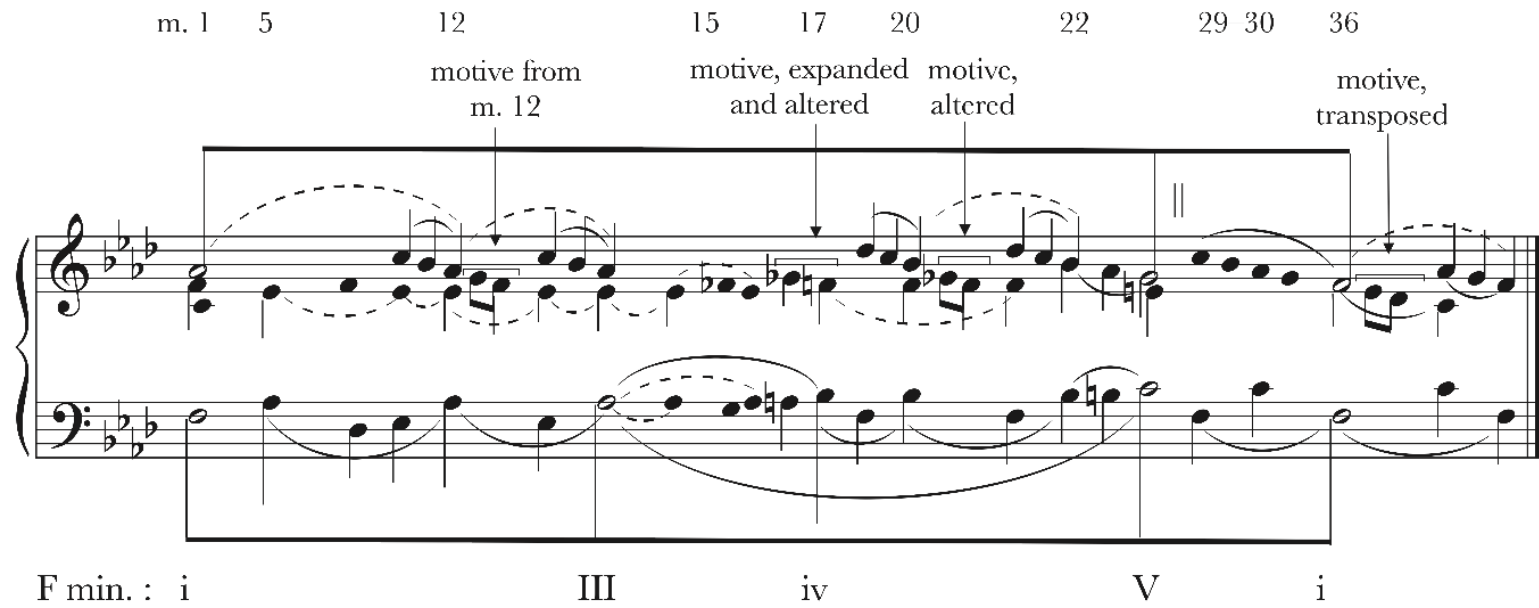

(c)

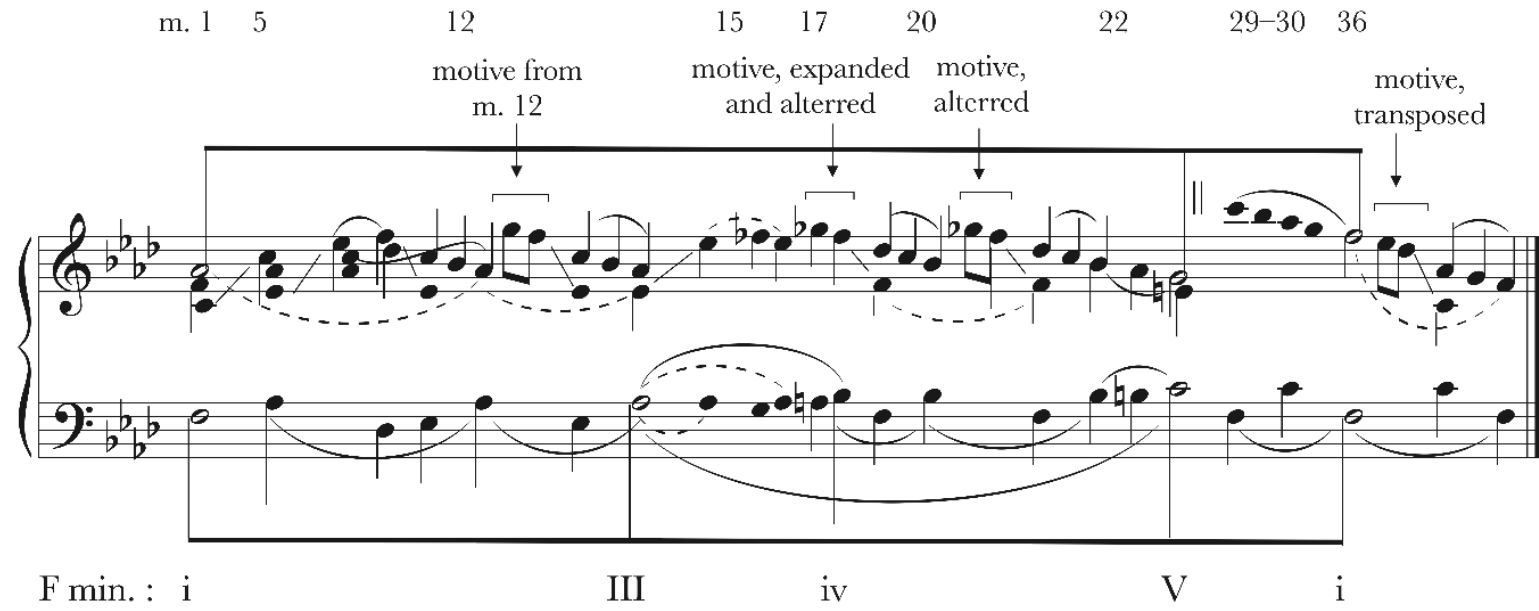

Fig. 11. Voice-leading sketch of entire Menuetto. 
(a) Voice-leading sketch of basic underlying framework.

(b) More detailed voice-leading model in which the register transfers have been removed.

(c) Voice-leading model with register transfers (cf. Fig. 11b).

The evolution of the motive across the movement arguably expresses a type of narrative. For instance, it could be understood to portray a quest narrative that culminates with a victory of sorts, in which the voice-leading "error" of the motive introduced in m. 12 is "corrected" and thereby "tamed" by its subsequent appearances. But there is also an alternative, less optimistic possible way of viewing the progress of the motive within this movement, one that conceives it as unfolding in the manner of a tragedy. According to this alternative scenario, the motive initially strives upward within a major-key setting. As the movement continues, however, the motive seems to accept its fate within a minor-key framework, abandoning its former attempts to forge upward. Whatever story one devises, certainly the interactions of the various appearances of this motive within its larger voice-leading context play a crucial role in the drama that underlies this movement.

\section{Heinrich Schenker's analysis}

The analysis presented above is not the first one to examine this movement with the aid of Schenkerian procedures. Almost a century ago, Heinrich Schenker published an extensive analysis of this entire sonata, including its Menuetto movement (SCHENKER, 1922, pp. 32-33 and Appendix). That this analysis is by Schenker himself does not necessarily make it more "Schenkerian" than ones proposed by anybody else, however. To be sure, Schenker did invent and develop much of the notation, terminology, and system of creating voice-leading models for the analytic tradition that bears his name, and he did examine at length its technical and philosophical bases. Yet the tonal principles upon which his analytic models are grounded were discussed in theoretical writings long before Schenker's time, and his successors-even those who are greatly influenced by his ideas-need not be limited by the specifics of Schenker's own thoughts.

Most notably, Schenker's followers should be careful not to get caught up in Schenker's unswervingly high opinion of his own analyses. Enormously self-confident, Schenker often suggested that his analytic interpretations-as well as his advice regarding details of performance-were the only correct ones, and he frequently belittled interpretations offered by other music scholars and performers. His chauvinistic rhetoric notwithstanding, we need not follow Schenker in this regard. Those who appeal to Schenkerian models ideally should recognize Schenker's own analyses for what they are: opinions by an individual regarding how one might fruitfully interpret a composition.

Nevertheless, many of Schenker's analytic interpretations are extremely powerful and convincing, and thus they often are worth taking seriously. Schenker's reading of the Menuetto of Beethoven's Op. 2, No. 1 is no exception in this regard. His voice-leading sketch of this movement (Fig. 12) comes from a relatively early publication, published over twenty years before the appearance of Schenker's most famous work, Der freie Satz (SCHENKER, 
1935). As such, the graphic notation used here is somewhat different than what has since become regarded as standard Schenkerian notation, which is based largely on Schenker's later practices. Even so, the reading presented in this voice-leading sketch is rather clear and easy to follow. As may be seen, Schenker's analysis of this Menuetto does not specifically address the motive first seen in $\mathrm{m}$. 12, which was the focus of my own analysis presented above. However, Schenker's analysis does offer many provocative interpretations of this movement's voice-leading details, a number of which I have adopted in my own reading.
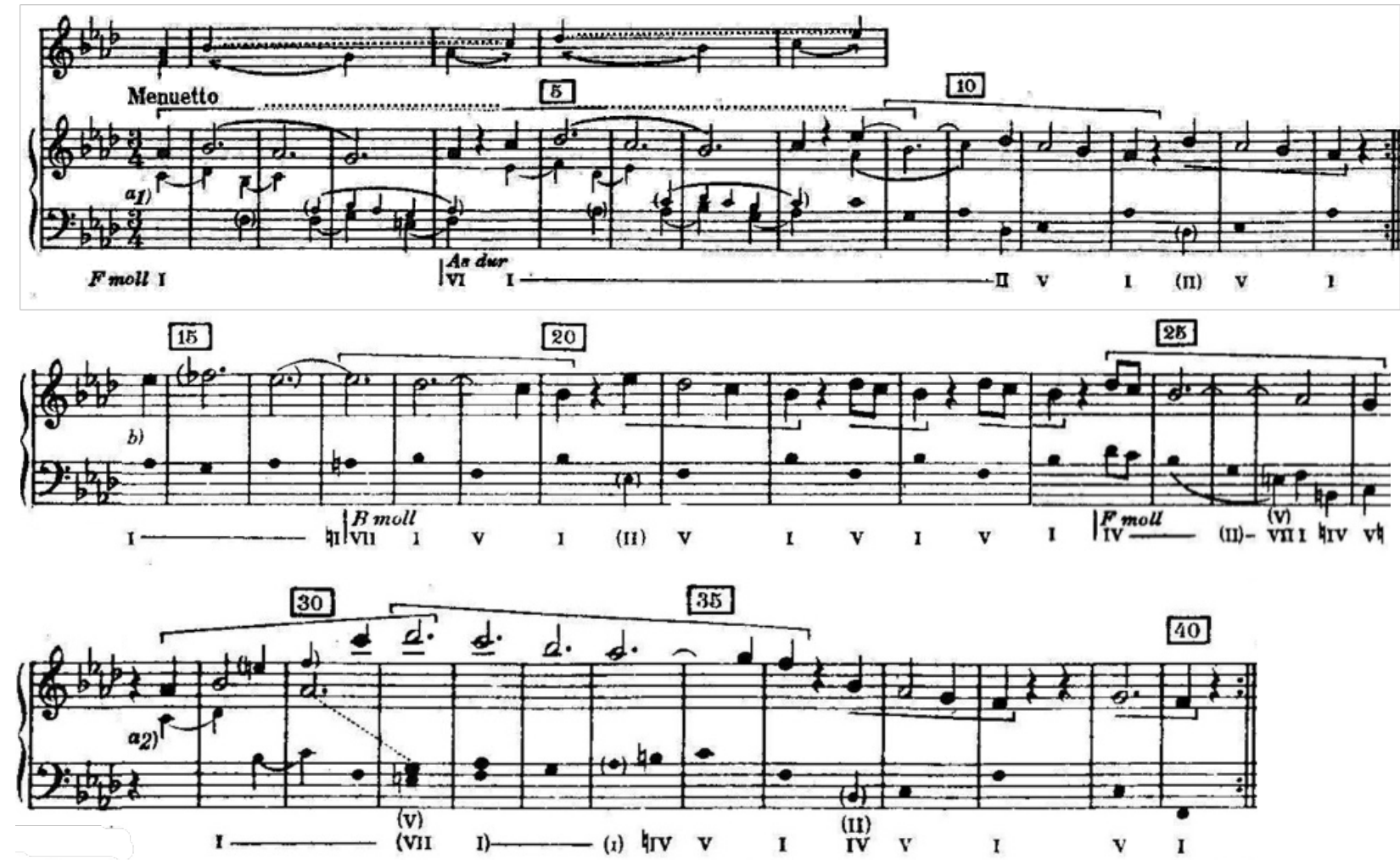

Fig. 12. Voice-leading analysis by Heinrich Schenker, from Tonwille 2, appendix.

My admiration for his interpretation of this movement notwithstanding, there nonetheless are certain aspects of Schenker's analysis that I question. For instance, consider his suggestion that the tonic chord of $\mathrm{m}$. 2 serves as a passing harmony, as indicated by the slur between B-flat and $G$ in the top voice in mm. 1-3 of Fig. 12. As shown in Fig. 13a, this creates a voice-leading contradiction between the implied soprano and tenor voices. More 
questionable is Schenker's interpretation of a stepwise line leading from A-flat up to E-flat in $\mathrm{mm}$. 1-8 (Fig. 13b), in which the implied chordal sevenths in $\mathrm{mm} .1$ and 5 are portrayed as resolving upward.

(a)

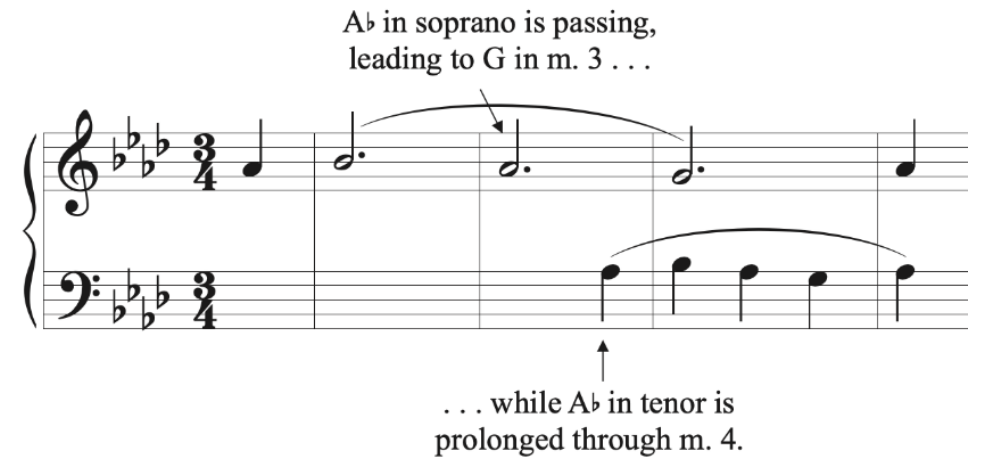

m. 1 5

$\mathrm{Ab} \mathrm{Bb} \longrightarrow \mathrm{C}$

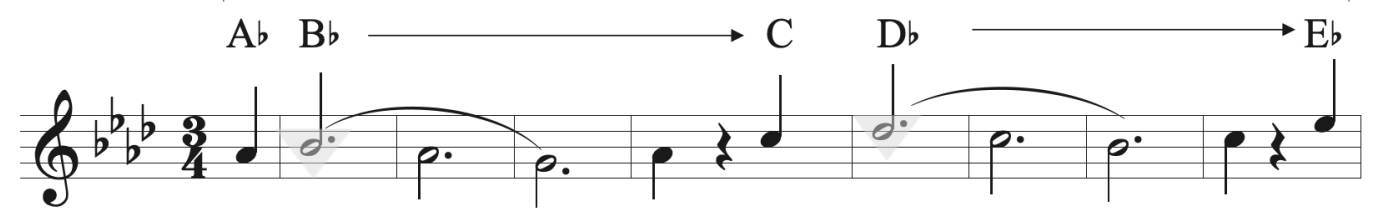

(b)

Schenker suggests that the chordal dissonances $\mathrm{B} b$ in $\mathrm{m} .1$ and $\mathrm{D}$ b in $\mathrm{m} .5$ lead upward (to $\mathrm{C}$ and $\mathrm{E}$, respectively).

Fig. 13. Clarifications of Schenker's interpretation shown in Example 10.

(a) Detail showing imitation (and voice-leading contradiction) between implied soprano and tenor voices in mm. 1-4 (cf. reading in Fig. 3 above).

(b) Detail showing linear progression of a fifth in the soprano voice in $\mathrm{mm}$. 1-8.

Another issue I have with Schenker's reading is its portrayal of the top voice in $\mathrm{mm}$. 14-18. At this point, as the music approaches a cadence in B-flat minor, his voice-leading sketch shows a descending line in the top voice. With this descending line, Schenker evidently attempts to demonstrate a voice-leading parallelism with what was seen at the previous cadence, in A-flat major; Schenker highlights this parallelism with brackets above the staff in mm. 8-12 and 17-20. In doing so, however, Schenker arguably underplays the role of the more salient and characteristic ascending sequence that occurs at this point. Such a sequence from III to iv is extremely typical for the opening of a B section within a rounded binary form movement. Much as the harmonies and bass of $\mathrm{mm}$. 15-16 are transposed up a step in mm. 17-18, so I would argue that the underlying voice leading of top voice is best understood to be transposed up a step here as well. Fig. 14a depicts Schenker's reading of this 
passage, albeit using the graphic notation typical of his later publications. For comparison, Fig. 14b shows my own preferred reading of these measures. Fig. 14c proposes an underlying voice-leading derivation of $\mathrm{mm}$. 14-18 that explains how parallel fifths are avoided within this ascending sequence.

(a) Schenker's reading:

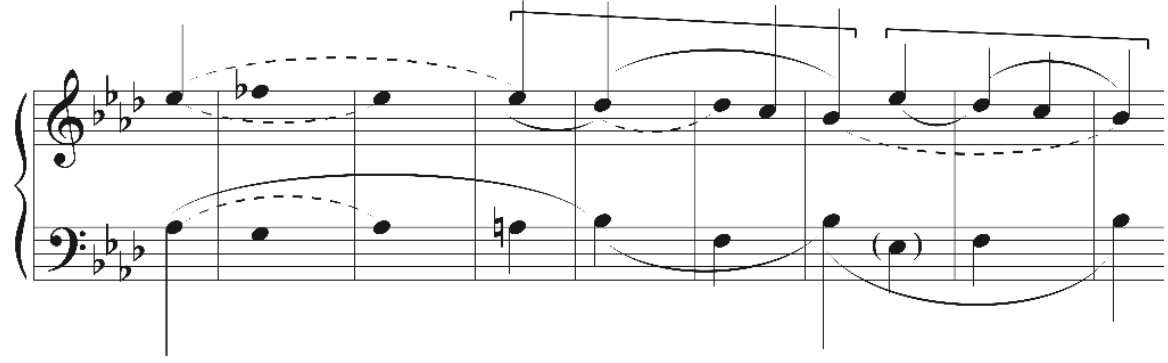

(b) My preferred reading:

m. 15

17

ascending sequence in the bass counterpointed by ascent in top voice

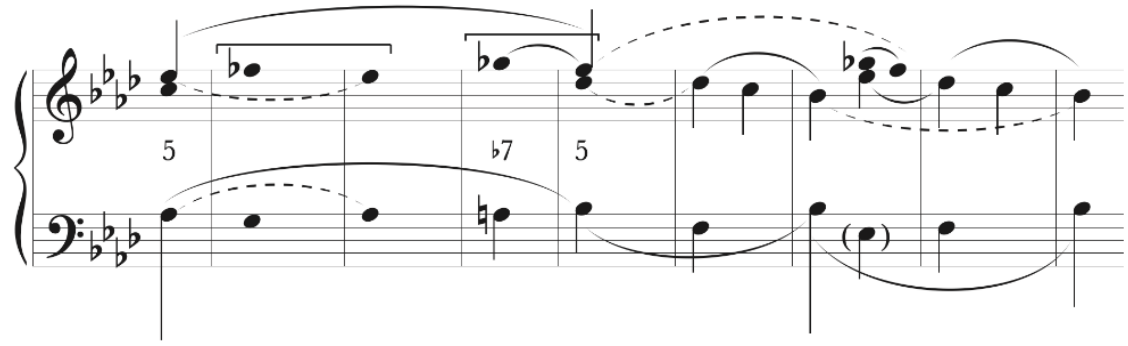

(c)
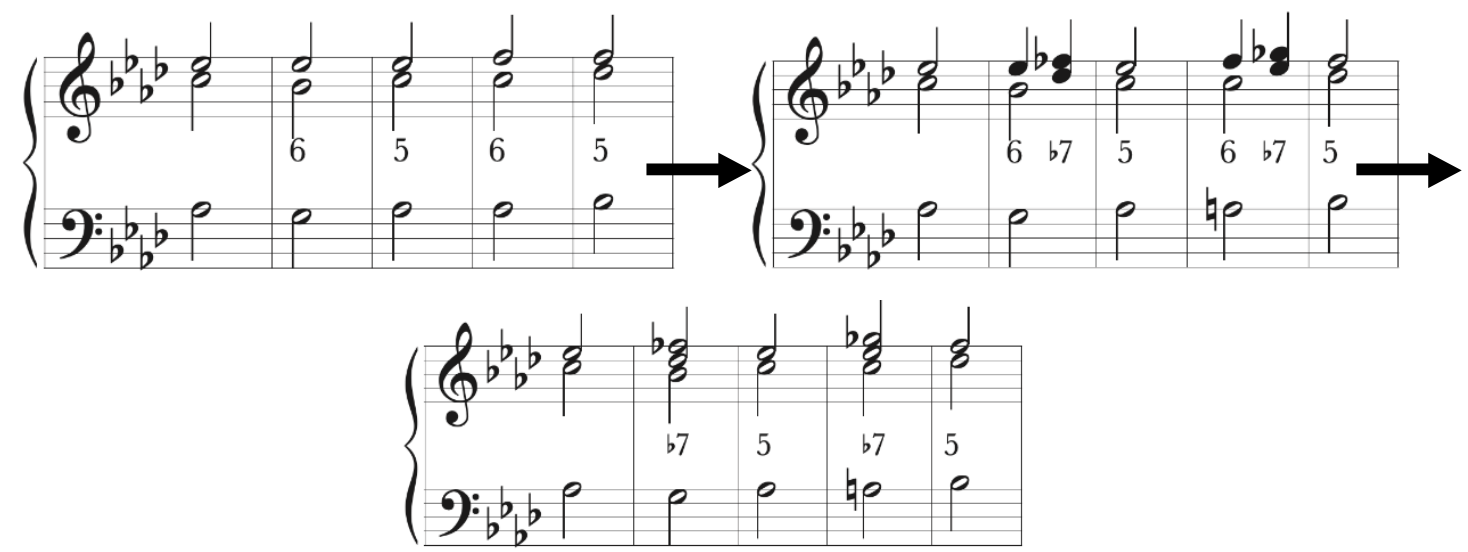

Fig. 14. Voice leading of mm. 14-20.

(a) Schenker's reading, adapted so as to use notation typical of his later publications. 
(b) My preferred reading, using standard Schenkerian notation (cf. Fig. 7a above).

(c) Proposed voice leading derivation for mm. 14-18, showing how parallel fifths are avoided in moving from A-flat major to B-flat minor.

Despite these quibbles with Schenker's reading, I nonetheless find many of its aspects to be quite captivating. His attempts to demonstrate interactions between the large-scale and small-scale events in this movement are especially inspiring. Note, for instance, how his analysis helps underscore dramatic nuances associated with the interplay between stepwise ascending and descending motions, which Schenker highlights with brackets in his sketch. In his accompany discussion, Schenker pays particular attention to the descending fifth-spans, which he claims form a large descending pattern (Fig. 15). Note how this large descending pattern leads first to a conclusion on the pitch A-flat ( $\mathrm{mm} .8-11)$, then to $\mathrm{G}(\mathrm{mm}$. 24-28), and finally to the tonic, F (mm. 31-36). As such, this pattern could be understood to frame the entire Menuetto with a huge motion toward tonal closure that extends across the sections. Notice that the pitches that mark the ends of these fifth-spans-A-flat, G, and F-correspond to the main notes of the top line (the ones attached to the upper beam) in my sketches of the entire movement seen in Fig. 11 above (cf. also Fig. 18 below).

mm. 8-11

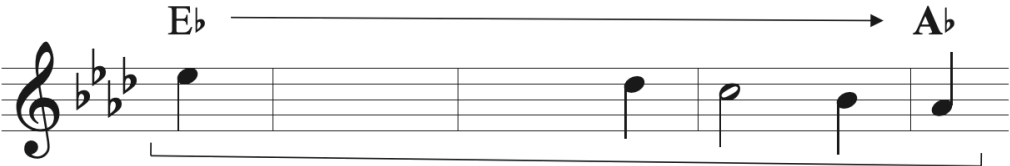

mm. 24-28
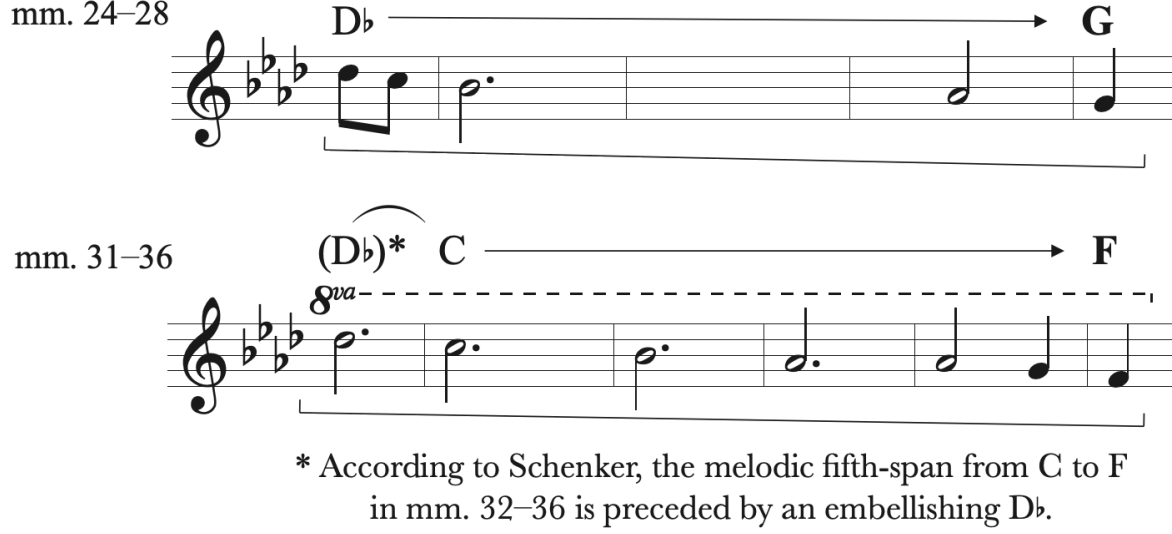

Fig. 15. Descending pattern of melodic fifth-spans discussed by Schenker.

Schenker's use of incomplete brackets, which are found below the staff in $\mathrm{mm} .12-13$, 20-24, and 36-40, helps underscore another intriguing dramatic maneuver within this movement. Specifically, these incomplete brackets call attention to the gradual fragmentation of the descending lines toward the ends of phrases, which allows each of the phrases to gently taper off. An especially fascinating twist that relates to this fragmentation appears toward the end of the Menuetto's middle section (Fig. 16). At this point, the D-flat-C-B-flat third-spans of $\mathrm{mm}$. 22-24 (shortened versions of the preceding E-flat-D-flat-C-B-flat fourth-span of $\mathrm{mm} .20-22$ ) are suddenly replaced by a long linear descent. Consequently, in $\mathrm{m} .24-28$, a 
fourth-span $(\mathrm{E} b$ to $\mathrm{B} b) \ldots$ shortened to third-span $(\mathrm{D} b$ to $\mathrm{B} b) \ldots$ surges forward with fifth-span

line $s i$

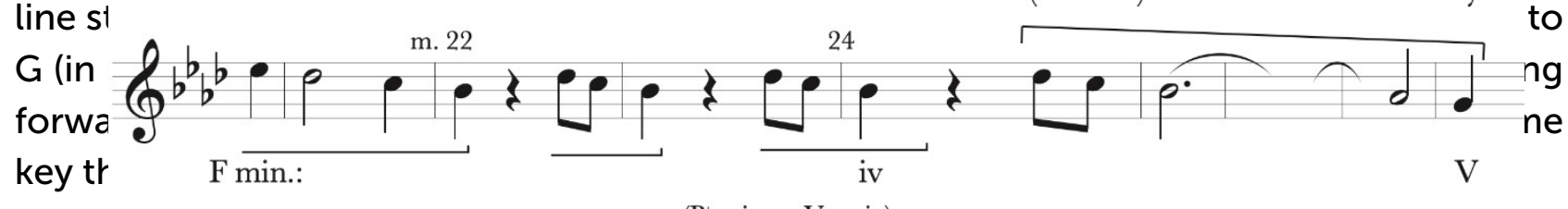

(Bb min.: $\quad \mathrm{V} \quad \mathrm{i}$ )

Fig. 16. Detail of Schenker's reading of the last beat of m. 20 through m. 28, showing Schenker's brackets that highlight dramatic shortening and expansion of descending linear progressions.

Another aspect of Schenker's interpretation that deserves special mention is his reading of a harmonic elision in mm. 33-34, toward the conclusion of the $A$ ' section. At this moment, an expected motion to $\mathrm{i}^{6}$ of $\mathrm{F}$ minor is replaced by a surprising move to $\mathrm{vii}^{\circ 7}$ of $\mathrm{V}$ (Fig. 17). Schenker underlines this harmonic elision with parentheses in his voice-leading sketch (see m. 34 of Fig. 12 above). He evocatively describes this as involving "a highly effective skipping of the bass tone A-flat (the $\mathrm{I}^{6}$ ) by immediately grasping natural-IV7-apparently indicating impatience and passion (notice how the forte has sforzando accents heaped upon it)."6
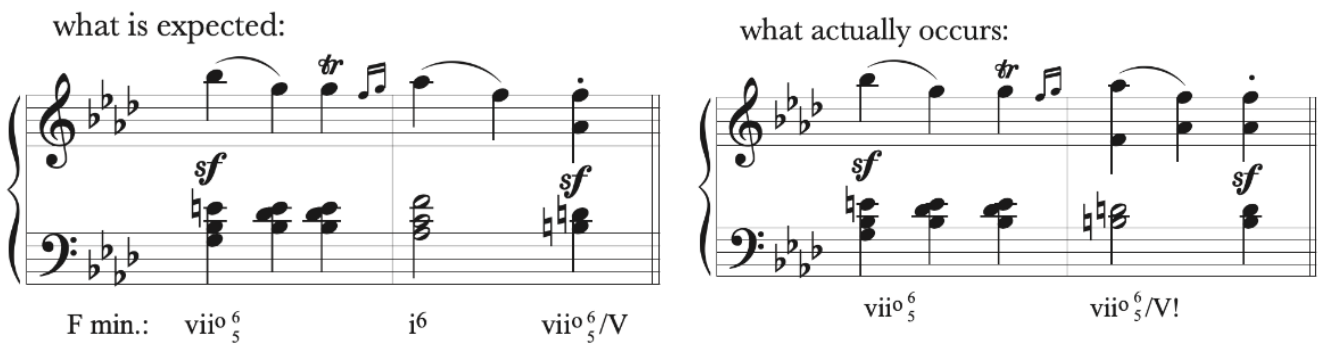

Fig. 17. Harmonic elision discussed by Schenker: comparison of what is expected and what occurs in mm. 33-34.

Schenker's evocative language seen in the quotation at the end of the previous paragraph is typical of his writings. Contrary to what is often assumed, Schenker arguably focused more on elucidating the expressive content of music than on explicating musical coherence for its own sake. Indeed, such focus on the expressive aspects of musical structure is something that I feel is reflected in the best writings by Schenker's followers, ${ }^{7}$ and it is an attitude that I have tried to emulate within this essay.

Schenker's analysis does not provide a reading of this movement's background structure. In other words, Schenker does not depict an underlying Urlinie or Ursatz for the Menuetto,

6 In T. 34 beim Basse ein höchst wirksames Überspringen des Tones As (als Sextakkordes der I. Stufe) und ein sofortiges Ergreifen der \$IV7, offenbar ein Zug von Ungeduld und Leidenschaft (s. bei forte noch die gehäuften Sforzato-Akzente).

7 See, for instance, OSTER, 1949; SCHACHTER, 1995 and 1999; SAMAROTTO, 2004 and 2007; as well as (in reference to vocal music) SUUPÄÄ, 2014; TERRINGO, 2016; and MARTIN, 2018; among many others. 
as he likely would have done with an analysis later in his career. ${ }^{8}$ Nevertheless, a background tonal framework would be simple enough to construct for this movement, such as is proposed in Fig. 18. Following the initial affirmation of the tonic of the home key in $\mathrm{mm}$. 1-4, the deep-level harmonies shown here-i-III-iv-V-I-are each emphasized by strong cadences, thereby allowing for this large-level harmonic framework to be easily perceived.

Significantly, the pitches of the Urlinie depicted in Fig. 18, much like the bass pitches of this Ursatz, all appear or are implied at pivotal moments within the movement. Furthermore, these pitches-A-flat-G-F-are the very ones emphasized at the end of each of the descending fifth-spans that were mentioned by Schenker (see Fig. 15 above). In all, this Urlinie helps represent the tonal narrative that embraces the entire movement, in which the relative stability of the opening measures is succeeded by a state of tonal tension, ultimately leading to an arrival of tonal closure at the movement's conclusion.

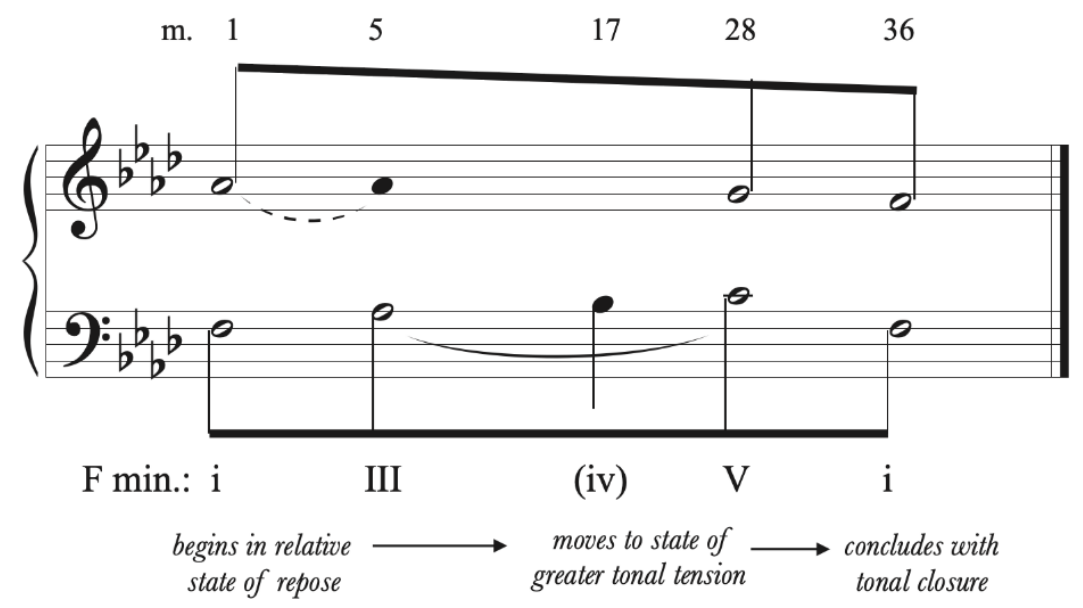

Fig. 18. Depiction of Ursatz for the entire movement (cf. Fig. 11)

It should be noted that within a well-formed Ursatz, a pitch in the top voice does not need to belong to the same harmony as bass note below it. All that is required is that the outer voices coordinate with each other in a contrapuntally sensible manner, as is certainly the case with the model of the Ursatz shown in Fig. 18. Thus, in $\mathrm{m}$. 17, no problem arises from the clash between the bass B-flat and the (implicitly sustained) A-flat of the Urlinie, since the B-flat could be understood to function as passing tone.

One could also plausibly represent this movement's deep-level tonal structure with an

8 Regarding the concepts of the Ursatz (estrutura fundamenta) and the Urlinie (linha fundamental) see GERLING; BARROS, 2020, pp. 13-15 and 18-20. Incidentally, that Schenker's voice-leading sketch reproduced in Fig. 12 concentrates largely on the foreground level contributes to its relative transparency and visual clarity, especially when compared to analyses that seek to combine many levels within the same voice-leading sketch, such as is typical of Schenker's later published analyses or as seen in my own multi-level analytic sketches of Figs. 11b and c. 
Urlinie that begins from $\hat{5}(C)$, rather than $\hat{3}$ (A-flat), without greatly affecting the overall interpretation of the movement's structure or narrative impact. Such a reading is proposed in Fig. 19. With this Ursatz model, the first note of the Urlinie is implied at the outset, not appearing on the surface of the music until m. 5. Nevertheless, here, too, each of the notes of the Urlinie are emphasized by appearing at pivotal moments within the form.

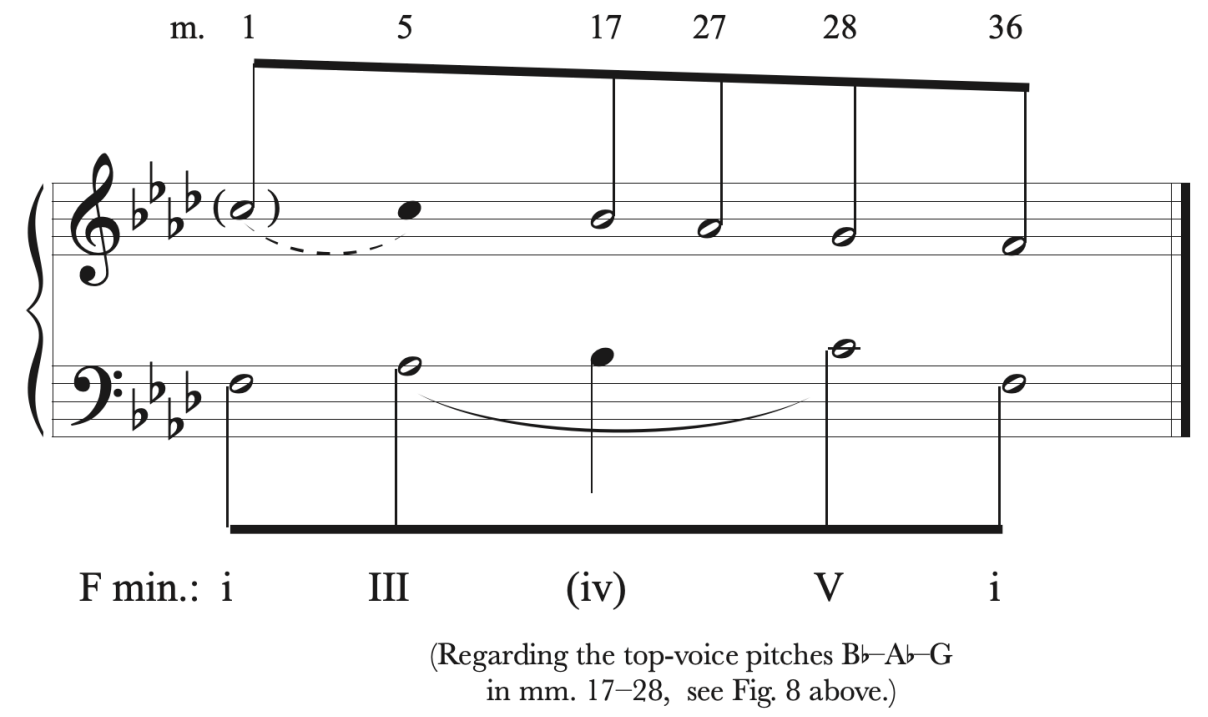

Fig. 19. Another possible depiction of the Ursatz for the entire movement, with the Urlinie starting from C (), rather than A-flat.

In any case, the deepest level of structure taken by itself is hardly the most important feature of this or any Schenkerian analysis. Rather, the most significant benefit of a Schenkerian analysis is the way in which it can help one explore and interpret ways in which the different levels of voice-leading may be comprehended as interacting with each other. Through such means, even a small gesture-such as the one seen in m. 12 of Beethoven's Menuetto-can be understood to have a bearing not only on its immediate context, but also on the phrase, section, and entire movement within which it resides. Sensitivity to such interactions between the large and small, such as Schenkerian analysis can help afford, in turn can profoundly enrich one's experience of a composition. 


\section{References}

Gerling, C. G.; Barros, G. Glossário de termos schenkerianos, rev. A. L. Moreira and I. G. Nabuco. Salvador: TEMA, 2020.

MARTIN, A. Sunken II Chords and Inwardness: A Correspondence Complex in Robert Schumann's Liederjahr Songs. Ph.D. diss., CUNY, 2018.

OSTER, E. The Dramatic Character of the Egmont Overture. Musicology, v.2, n.3, p.269$285,1949$.

SAMAROTTO, F. Determinism, Prediction, and Inevitability in Brahms's Rhapsody in E-flat major, op. 119, no. 4. Theory and Practice, v.32, p.69-99, 2007.

SAMAROTTO, F. Sublimating Sharp : An Exercise in Schenkerian Energetics. Music Theory Online, v.10, n.3, 2004.

SCHACHTER, C. The Triad as Place and Action. Music Theory Spectrum, v.17, n.3, p.149169, 1995.

SCHACHTER, C. Structure as Foreground 'das Drama des Ursatzes,' in Schenker Studies 2. Cambridge, Cambridge University Press, p. 298-314, 1999.

SCHENKER, H. Der freie Satz. Vienna: Universal Edition, 1935.

SCHENKER, H. Beethoven: Sonate opus 2 Nr. 1. Tonwille 2. Vienna: A. Gutmann Verlag, p.32-33 and Appendix, 1922.

SUURPää, L. Death in Winterreise: Musico-Poetic Associations in Schubert's Song Cycle. Bloomington Indiana: Indiana University Press, 2014.

TERRIGNO, L. The Protagonist's Experience: Temporality, Narrative, and Harmonic Process in Brahms's Solo Lieder. Ph.D. diss., CUNY, 2016. 